\title{
Genetic diversity analysis of major Sri Lankan goat populations using microsatellite and mitochondrial DNA D-loop variations
}

\author{
Pradeepa Silva $^{a, *}$, C.M.B. Dematawewa ${ }^{a}$, Maheshika Kurukulasuriya ${ }^{a}$, \\ Yuri T. Utsunomiya ${ }^{\text {b }}$, José Fernando Garcia ${ }^{\text {b }}$, Rudolf Pichler ${ }^{c}$, A.K. Thiruvenkadan ${ }^{\mathrm{d}}$, \\ Saravanan Ramasamy ${ }^{\mathrm{d}}$, Jian-Lin Han ${ }^{\mathrm{e}}$, Kathiravan Periasamy ${ }^{\mathrm{c}}$ \\ a Faculty of Agriculture, University of Peradeniya, Peradeniya, Sri Lanka \\ b UNESP - Univ. Estadual Paulista, Faculdade de Medicina Veterinária de Araçatuba, Araçatuba, São Paulo, Brazil \\ ' Joint FAO/IAEA Division of Nuclear techniques in Food and Agriculture, International Atomic Energy Agency, Vienna, Austria \\ d Tamil Nadu Veterinary and Animal Sciences University, Chennai, Tamil Nadu, India \\ e CAAS-ILRI Joint Laboratory on Livestock and Forage Genetic Resources, Institute of Animal Science, Chinese Academy of Agricultural Sciences (CAAS), \\ Beijing, China
}

\section{A R T I C L E I N F O}

Article history:

Available online 21 December 2016

\section{Keywords:}

DNA

Microsatellite

Genetic diversity

mtDNA D-loop

Haplogroup

Goat

Sri Lanka

\begin{abstract}
A B S T R A C T
The present study aimed at the genetic characterization of five major goat populations of Sri Lanka including four indigenous populations (Jaffna Local - JFL, Kottukachchiya - KOT, Southern - SLS and North Central - SNC) and one stabilized crossbred (German Boer x indigenous goats, also known as "Sri Lankan Boer" - SLB). Genetic diversity was evaluated using 15 microsatellite markers and the mitochondrial DNA D-loop variation. Allelic diversity and observed and expected heterozygosities were moderate, but less than Eurasian and Indian goat breeds. The overall mean estimated inbreeding coefficient $\left(\mathrm{F}_{\mathrm{IS}}\right)$ was 0.069 and significant heterozygote deficiency was detected in JFL $(P<0.001)$, KOT $(P<0.01)$ and SLS $(P<0.05)$, indicating population-specific drift or selection of the loci assessed. Genetic differentiation among populations was low and the phylogenetic clustering pattern was in line with the geographical location of goat populations. Although pair-wise Cavalli-Sforza and Edwards chord distance clustered SLS and SLB separately from the rest of the populations, Bayesian clustering clearly showed lack of discrete genetic structure in Sri Lankan goat populations despite significant morphological and phenotypic differences among them. Mitochondrial DNA D-loop sequences revealed significantly high haplotype diversity with the existence of maternal haplogroups ' $\mathrm{A}$ ' and 'B'. Analysis of mtDNA sequences indicated maternal origins of Jaffna Local, Kotukachchiya and Sri Lankan South distinct from the other goat populations.
\end{abstract}

(C) 2017 International Atomic Energy Agency. Published by Elsevier B.V. All rights reserved.

\section{Introduction}

Goats in Sri Lanka represent 23\% of the total Sri Lankan ruminant population (Department of Census and Statistics, 2011), and $72 \%$ of the goat population is distributed in dry areas (Department of Animal Production and Health, 2010a). At present, the local goat populations are thriving well under the existing environment and management systems (Chandrasiri, 2002; Silva et al., 2009). Currently, three main categories of goat genetic resources can be identified in Sri Lanka, (1) native (or indigenous), (2) locallyadapted exotic breeds and (3) crossbreds. The exotic pure breeds have been introduced into Sri Lanka from time to time in order

\footnotetext{
* Corresponding author.

E-mail address: pradeepas@pdn.ac.lk (P. Silva).
}

to improve the performance of native goats. As indicated in the livestock breeding policy of the country (Department of Animal Production and Health, 2010b), the strategy for the extensively managed local goats is genetic upgrading unto a recommended level of exotic inheritance using breeds like Jamunapari, Beetal and German Boer. In all these recommendations, improvement of productivity has been considered as the primary objective (Chandrasiri, 2002). A goat development project was implemented during the 1980s to develop the "Sri Lankan Boer" (SLB), by crossing local goats with Boer goats from Germany for the purpose of improving meat production (Jayasinghe et al., 2003). The resulting SLB goats were distributed in the field and intercrossed for several generations. The status of the stabilized crossbred is not known at present.

The majority of Sri Lankan goats are indigenous type, which are prolific and tolerant to the local environment, but are poor meat 
producers with slow growth and small mature body size. There are four geographically isolated and phenotypically well described goat populations in different regions of Sri Lanka. Jaffna Local (JFL) is a dual purpose hardy goat population and is found in the Northern Peninsular region with a black coat and with or without white patches. The estimated population size of Jaffna Local goat is around 67,760. Kottukachchiya (KOT) breed is a meat type animal and is distributed in the North Western region. This breed originated from non-descript animals imported for slaughter from South India and crossed with selected local animals (Silva et al., 2010). KOT usually have a medium-sized slender body with long legs and a mostly black or mixed coat color. Goats from the North Central (SNC) region are mostly brown or brown with black patches and are reared mainly for meat. The estimated population size is 42,470 . The goat population from Southern region is also a meat type animal with variations in coat color. Animals have black or brown coat with white patches. The estimated population size is 14,690.

Although significant morphological differences exist among these indigenous Sri Lankan goat populations (Supplementary Fig. SF1a-e), little information is available on their genetic diversity and structure (Barker et al., 2001). Hence, the present study aimed at genetic characterization of four major indigenous goat populations of Sri Lanka along with SLB goats by using 15 microsatellite markers. Mitochondrial DNA D-loop region was sequenced to determine the maternal lineages and the phylogeography of Sri Lankan goats.

\section{Materials and methods}

\subsection{Samples and microsatellite genotyping}

Blood samples were collected from individuals representing five populations, out of which three were geographically isolated: JFL $(n=40)$, SLS $(n=43)$ and SNC $(n=43)$ and two were phenotypically well described (Chandrasiri, 2002; Jayasinghe et al., 2003): KOT $(n=41)$ and SLB $(n=26)$. The geographic locations of these goat populations are presented in Fig. 1. Jugular blood was collected in tubes with EDTA and DNA purification was performed using the salting out protocol (Miller et al., 1988). DNA samples were then stored at $-20^{\circ} \mathrm{C}$ until further processing. The laboratory work flow consisted of the following steps: (1) DNA purification; (2) DNA quality and quantity estimation by agarose gel electrophoresis and spectrophotometry; (3) PCR amplification using microsatellite primers; (4) PCR product visualization in agarose gel electrophoresis; (5) preparation of PCR products for multiplex genotyping using a capillary sequencer (ABI 3730 DNA Analyzer - Applied Biosystems) and (6) electropherogram analysis for allele size determination using GENEMAPPER software (Applied Biosystems). Fifteen ISAG/FAO recommended microsatellite markers for diversity analysis in goats were selected for the present study: ILSTS029, BMS1494, MAF035, SRCRSP3, BM1818, OARFCB20, OARAE54, ILSTS005, SPS113, CSRD247, INRA0132, MCM527, MAF70, ILSTS11 and ETH10 (FAO, 2011).

\subsection{Sequencing mitochondrial DNA D-loop region}

The mitochondrial DNA D-loop region was amplified and sequenced in a total of 42 samples (JFL (3), KOT (10), SLB (14), SLS (9) and SNC (6)) from five investigated goat breeds. Additionally, 41 Sri Lankan Jamunapari crossbred goats and 59 South Indian goats (Kanni Adu (12), Kodi Adu (8) and Tellichery (39)) were sequenced for comparative analysis. Primers were designed to amplify the $1607 \mathrm{bp}$ D-loop region by using the online tool Primer 3 version 4.0 (http://bioinfo.ut.ee/primer3-0.4.0/) and reference sequence KJ192209 (Doro et al., 2014). The primer sequences used were GTMT-F-5' CAGCAGCTAGCACCATTGAA-3' and GTMT-R-
5'AAGCGAGGCGTTGTAA GCTA-3'. Polymerase chain reaction (PCR) was performed in a total reaction volume of $20 \mu \mathrm{l}$ with the following cycling conditions: initial denaturation at $95^{\circ} \mathrm{C}$ for $15 \mathrm{~min}$ followed by 30 cycles of $95^{\circ} \mathrm{C}$ for $1 \mathrm{~min} ; 60^{\circ} \mathrm{C}$ for $1 \mathrm{~min}$; $72^{\circ} \mathrm{C}$ for $1 \mathrm{~min}$ with final extension at $72^{\circ} \mathrm{C}$ for $10 \mathrm{~min}$. Purified PCR products were sequenced using Big Dye Terminator Cycle Sequencing Kit (Applied Biosystems, USA) on an automated Genetic Analyzer ABI 3100 (Applied Biosystems, USA).

\subsection{Statistical analysis}

Individuals exhibiting more than $10 \%$ missing data (missing two or more genotypes out of 15 genotyped loci) were excluded from the analysis. Basic diversity parameters including observed number of alleles, observed and expected heterozygosity and fixation index were calculated using MICROSATELLITE ANALYZER (MSA) version 4.05 (Dieringer and Schlotterer, 2003). Deviations of heterozygosities from Hardy-Weinberg Equilibrium (HWE) were estimated by: (1) calculating the degree of within-population reduction in heterozygosity due to inbreeding for each population $\left(F_{\mathrm{IS}}\right)$ and $(2)$ exact tests of heterozygote excess and deficit for each marker and each population, as implemented in GENEPOP software. The neutrality of microsatellite markers used in this study was evaluated by $\mathrm{F}_{\mathrm{ST}}$ outlier approach as implemented in the software LOSITAN version 1 for windows (Antao et al., 2008), with 95\% confidence intervals. Pair-wise Cavalli-Sforza and Edwards chord distance was utilized to construct the dendrogram and radial tree following UPGMA algorithm using PHYLIP version 3.5 (Felsenstein, 1993). Analysis of molecular variance (AMOVA) and exact tests for Hardy Weinberg equilibrium were performed using ARLEQUIN version 3.1 (Excoffier et al., 2005). The genetic relationship observed in the dendrogram and radial tree was further tested by performing multidimensional scaling (MDS) analysis of pair-wise $\mathrm{F}_{\mathrm{ST}}$ values among populations using SPSS version 13.0. MDS is a multivariate ordination technique that helps to visualize the information contained in a genetic distance/differentiation matrix by reducing the dimensionality of data. It places the breeds in a two or three dimensional space such that between breed genetic distances of all possible pairs are preserved in the best possible way. Finally, a Bayesian clustering analysis was employed using STRUCTURE version 2.3.4 (Pritchard et al., 2000), assuming 2-5 clusters (K), with a burn in period of 500,000 and a run length of 500,000 iterations. For each $\mathrm{K}$, five replicates were performed and an admixture model with non-correlated allele frequencies was assumed in all runs.

Mitochondrial DNA sequences were edited using Codon Code Aligner version 3.7.1. Multiple sequence alignments and phylogenetic analysis was performed using MEGA version 5.01 (Tamura et al., 2011). Mitochondrial DNA diversity parameters including nucleotide diversity, haplotype diversity, average number of nucleotide differences were calculated using DnaSP, version 4.10 (Rozas, 2009). The mitochondrial haplotypes of Sri Lankan goats were analyzed after including reference sequences for each of the six goat maternal lineages as suggested by Naderi et al. (2007). The maximum likelihood method with Tamura-Nei model was used to construct phylogeny under the assumption of uniform mutation rates among polymorphic sites. Nearest neighbour interchange option was used to infer the tree. In order to establish the evolutionary relationship of Sri Lankan goats with goat populations of India, 336 mitochondrial DNA D-loop region sequences from nine breeds and one non-descript local population (AY155674AY156039; Joshi et al., 2004) were included for analysis. Frequency of different haplotypes, haplotype sharing, AMOVA and pair-wise $F_{S T}$ were estimated using ARLEQUIN 2.1. Pair-wise $F_{S T}$ derived from mtDNA haplotype frequency were utilized to perform principal components analysis using SPSS version 13.0. 


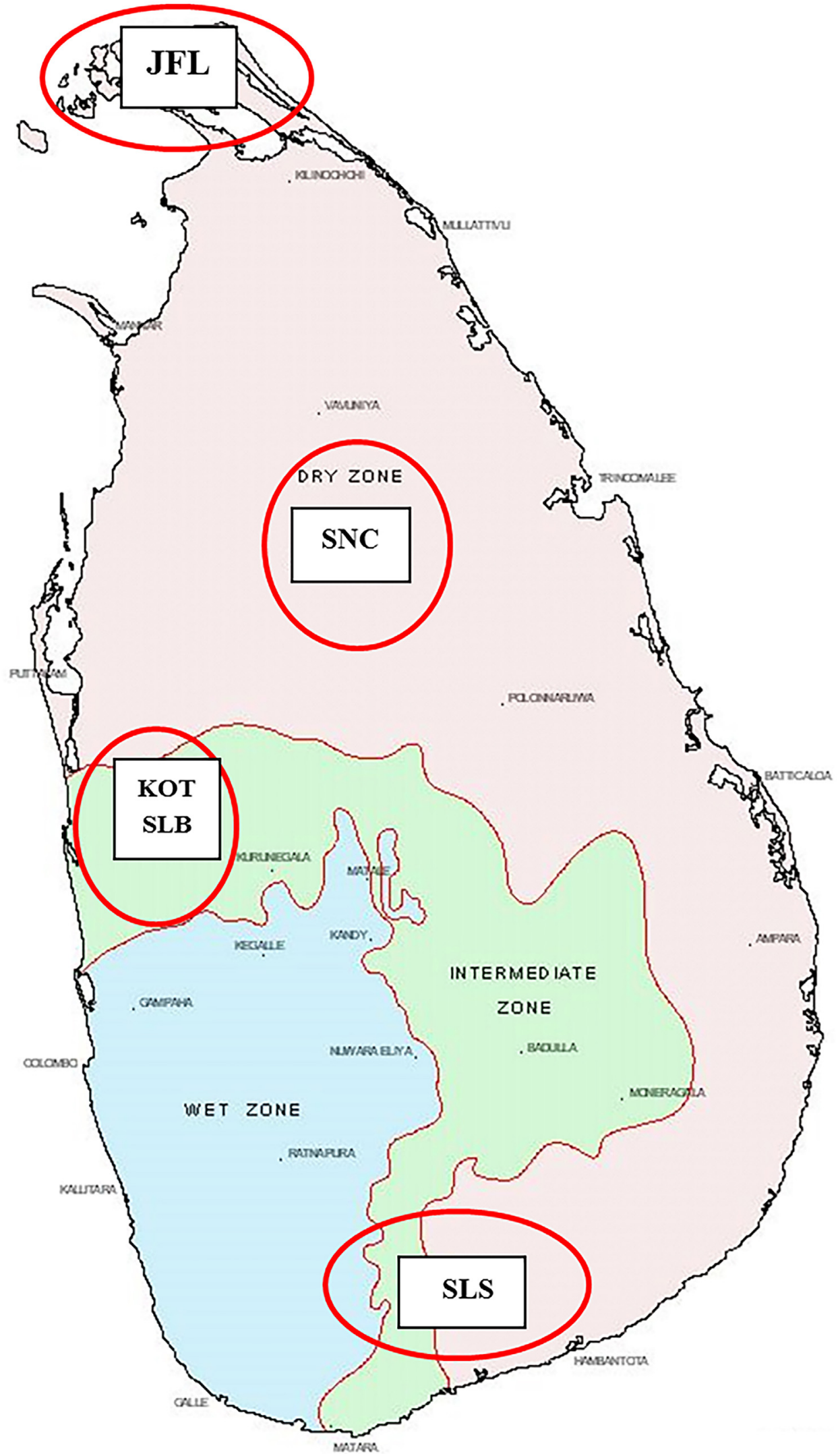

Fig. 1. Geographical locations of sampled goat populations in Sri Lanka. 
Table 1

Basic diversity indices of Sri Lankan goat populations at different microsatellite loci.

\begin{tabular}{|c|c|c|c|c|c|c|c|c|c|c|c|c|c|c|c|}
\hline \multirow[t]{2}{*}{ Locus } & \multicolumn{3}{|l|}{$\mathrm{JFL}$} & \multicolumn{3}{|c|}{ KOT } & \multicolumn{3}{|l|}{ SLB } & \multicolumn{3}{|l|}{ SLS } & \multicolumn{3}{|c|}{ SNC } \\
\hline & $\mathrm{n}_{\mathrm{a}}$ & $\mathrm{H}_{\mathrm{o}}$ & $\mathrm{H}_{\mathrm{e}}$ & $\mathrm{n}_{\mathrm{a}}$ & $\mathrm{H}_{\mathrm{o}}$ & $\mathrm{H}_{\mathrm{e}}$ & $\mathrm{n}_{\mathrm{a}}$ & $\mathrm{H}_{\mathrm{o}}$ & $\mathrm{H}_{\mathrm{e}}$ & $\mathrm{n}_{\mathrm{a}}$ & $\mathrm{H}_{\mathrm{o}}$ & $\mathrm{H}_{\mathrm{e}}$ & $\mathrm{n}_{\mathrm{a}}$ & $\mathrm{H}_{\mathrm{o}}$ & $\mathrm{H}_{\mathrm{e}}$ \\
\hline ILSTS029 & 6 & 0.225 & 0.233 & 7 & 0.268 & 0.309 & 5 & 0.269 & 0.251 & 6 & 0.256 & 0.277 & 8 & 0.326 & 0.317 \\
\hline BMS1494 & 4 & 0.564 & 0.580 & 4 & 0.512 & 0.528 & 4 & 0.538 & 0.565 & 3 & 0.442 & 0.503 & 3 & 0.442 & 0.458 \\
\hline MAF035 & 3 & 0.200 & 0.205 & 2 & 0.122 & 0.116 & 2 & 0.192 & 0.177 & 3 & 0.163 & 0.153 & 2 & 0.095 & 0.092 \\
\hline SRCRSP3 & 5 & 0.675 & 0.629 & 7 & 0.707 & 0.773 & 4 & 0.500 & 0.615 & 7 & 0.651 & 0.791 & 5 & 0.595 & 0.564 \\
\hline BM1818 & 10 & 0.600 & 0.614 & 9 & 0.488 & 0.537 & 4 & 0.654 & 0.542 & 7 & 0.488 & 0.521 & 7 & 0.581 & 0.573 \\
\hline OARFCB20 & 8 & 0.625 & 0.591 & 9 & 0.634 & 0.647 & 8 & 0.731 & 0.670 & 7 & 0.698 & 0.604 & 9 & 0.605 & 0.642 \\
\hline OARAE54 & 7 & 0.579 & 0.650 & 8 & 0.725 & 0.678 & 9 & 0.800 & 0.820 & 5 & 0.674 & 0.737 & 7 & 0.721 & 0.725 \\
\hline ILSTS005 & 5 & 0.375 & 0.414 & 4 & 0.390 & 0.437 & 3 & 0.308 & 0.363 & 5 & 0.349 & 0.440 & 3 & 0.349 & 0.379 \\
\hline SPS113 & 7 & 0.800 & 0.742 & 7 & 0.683 & 0.742 & 5 & 0.731 & 0.688 & 6 & 0.698 & 0.715 & 5 & 0.698 & 0.677 \\
\hline CSRD247 & 9 & 0.825 & 0.827 & 9 & 0.585 & 0.773 & 7 & 0.846 & 0.855 & 9 & 0.884 & 0.822 & 10 & 0.833 & 0.758 \\
\hline INRA0132 & 4 & 0.225 & 0.368 & 3 & 0.220 & 0.364 & 3 & 0.115 & 0.247 & 3 & 0.209 & 0.266 & 5 & 0.279 & 0.393 \\
\hline MCM527 & 7 & 0.625 & 0.672 & 7 & 0.707 & 0.780 & 6 & 0.846 & 0.789 & 7 & 0.581 & 0.619 & 7 & 0.535 & 0.590 \\
\hline MAF70 & 10 & 0.825 & 0.863 & 12 & 0.805 & 0.858 & 7 & 0.692 & 0.838 & 9 & 0.698 & 0.802 & 10 & 0.651 & 0.807 \\
\hline ILSTS11 & 5 & 0.425 & 0.473 & 4 & 0.390 & 0.385 & 4 & 0.808 & 0.725 & 4 & 0.419 & 0.454 & 5 & 0.605 & 0.576 \\
\hline ETH10 & 3 & 0.325 & 0.510 & 3 & 0.512 & 0.485 & 4 & 0.462 & 0.548 & 2 & 0.581 & 0.506 & 4 & 0.419 & 0.459 \\
\hline Mean & 6.2 & 0.526 & 0.558 & 6.3 & 0.517 & 0.561 & 5.0 & 0.566 & 0.579 & 5.5 & 0.519 & 0.547 & 6.0 & 0.516 & 0.534 \\
\hline
\end{tabular}

$n_{a}=$ Observed number of alleles; $H_{0}=$ Observed heterozygosity; $H_{e}=$ Expected heterozygosity .

Table 2

Heterozygosity deficit $\left(\mathrm{F}_{\mathrm{IS})}\right.$ and test for Hardy-Weinberg equilibrium at different microsatellite loci in Sri Lankan goat populations.

\begin{tabular}{|c|c|c|c|c|c|c|c|c|c|c|}
\hline \multirow[t]{2}{*}{ Locus } & \multicolumn{2}{|l|}{ JFL } & \multicolumn{2}{|l|}{ KOT } & \multicolumn{2}{|l|}{ SLB } & \multicolumn{2}{|l|}{ SLS } & \multicolumn{2}{|l|}{ SNC } \\
\hline & $\mathrm{F}_{\mathrm{IS}}$ & P-value & $\mathrm{F}_{\mathrm{IS}}$ & P-value & $\mathrm{F}_{\mathrm{IS}}$ & P-value & $\mathrm{F}_{I S}$ & P-value & $\mathrm{F}_{\mathrm{IS}}$ & P-value \\
\hline ILSTS029 & 0.029 & 0.188 & 0.126 & 0.039 & -0.083 & 1.000 & 0.073 & 0.217 & -0.034 & 0.356 \\
\hline BMS1494 & 0.021 & 0.341 & 0.025 & 0.479 & 0.038 & 0.268 & 0.117 & 0.396 & 0.030 & 0.761 \\
\hline MAF035 & 0.017 & 0.130 & -0.059 & 1.000 & -0.097 & 1.000 & -0.071 & 1.000 & -0.044 & 1.000 \\
\hline SRCRSP3 & -0.081 & 0.393 & 0.079 & 0.231 & 0.180 & 0.291 & 0.173 & 0.001 & -0.062 & 0.991 \\
\hline BM1818 & 0.017 & 0.633 & 0.087 & 0.289 & -0.220 & 0.787 & 0.058 & 0.746 & -0.021 & 0.406 \\
\hline OARFCB20 & -0.065 & 0.935 & 0.014 & 0.586 & -0.103 & 0.949 & -0.163 & 0.910 & 0.053 & 0.631 \\
\hline OARAE54 & 0.104 & 0.214 & -0.076 & 0.141 & 0.015 & 0.219 & 0.080 & 0.259 & 0.000 & 0.081 \\
\hline ILSTS005 & 0.090 & 0.052 & 0.102 & 0.212 & 0.145 & 0.284 & 0.204 & 0.054 & 0.074 & 0.584 \\
\hline SPS113 & -0.085 & 0.789 & 0.075 & 0.288 & -0.074 & 0.611 & 0.018 & 0.410 & -0.037 & 0.701 \\
\hline CSRD247 & -0.004 & 0.065 & 0.239 & 0.002 & 0.001 & 0.274 & -0.082 & 0.007 & -0.107 & 0.782 \\
\hline INRA0132 & 0.386 & 0.010 & 0.394 & 0.006 & 0.530 & 0.014 & 0.208 & 0.227 & 0.287 & 0.071 \\
\hline MCM527 & 0.064 & 0.198 & 0.088 & 0.548 & -0.084 & 0.663 & 0.056 & 0.112 & 0.089 & 0.521 \\
\hline MAF70 & 0.039 & 0.055 & 0.056 & 0.154 & 0.167 & 0.009 & 0.126 & 0.273 & 0.190 & 0.014 \\
\hline ILSTS11 & 0.097 & 0.039 & -0.019 & 0.205 & -0.127 & 0.662 & 0.073 & 0.341 & -0.055 & 0.960 \\
\hline ETH10 & 0.361 & 0.003 & -0.063 & 1.000 & 0.150 & 0.428 & -0.157 & 0.370 & 0.083 & 0.166 \\
\hline Mean ${ }^{*}$ & 0.066 & 3 & 0.071 & 3 & 0.029 & 2 & 0.048 & 2 & 0.030 & 1 \\
\hline
\end{tabular}

* Values under P-value indicate the number of loci that deviated from HWE within each goat population.

\section{Results and discussion}

\subsection{Genetic variability and test for Hardy-Weinberg equilibrium}

A total of 2895 genotypes were generated at 15 microsatellite loci across 193 animals belonging to five Sri Lankan goat populations. The basic diversity measures, allelic diversity, observed heterozygosity and expected heterozygosity of the five Sri Lankan goat populations are presented in Table 1 . A total of 130 alleles were observed across all five goat populations with an overall mean of 8.7 per locus ranging from 4 (BS1494 and MAF035) to 16 (MAF70). The overall mean observed and expected heterozygosity per locus was 0.526 and 0.564 , respectively. The overall observed heterzygosity in Sri Lankan goats varied from 0.151 (MAF035) to 0.792 (CSRD0247) while the overall expected heterozygosity ranged between 0.145 (MAF035) and 0.852 (MAF70). The genetic variability was observed to be similar across Sri Lankan goat populations. Between populations, the mean observed number of alleles varied from 5 (SLB) to 6.3 (KOT) while the mean observed and expected heterozygosity varied from 0.516 (SNC) to 0.566 (SLB) and from 0.534 (SNC) to 0.579 (SLB), respectively. The allelic diversity in Sri Lankan goats was found to be in a similar range as reported for South East Asian [Malaysia (Marini et al., 2014); Thailand (Anothaisinthawee et al., 2012)] and South Asian goats [Pakistan (Vahidi et al., 2014); Bangladesh (Afroz et al., 2010)]. However, higher allelic diversity was reported in Indian (Rout et al., 2008), Iranian (Vahidi et al., 2014), Turkish (Bulut et al., 2016), Saudi Arabian (Canon et al., 2006), Nigerian (Murital et al., 2015), North African (Elbeltagy et al., 2016) and European (Canon et al., 2006) goats. Allelic diversity in Korean goats (Kim et al., 2002) was observed to be much lower than Sri Lankan goats. Similar trend was observed with respect to gene diversity (expected heterozygosity) among goat populations from these regions. The genetic diversity was found to be higher in goats from West Asia, Europe and India followed by South Asian and South East Asian goats while it was lowest in East Asian goats. This decreasing gradient of genetic diversity is in line with increasing geographical distance from the proposed centers of goat domestication (Lenstra et al., 2016). Archaeological and mitochondrial DNA variations showed the domestication of goats to have taken place 10,000 years ago in a wide geographic area centered around Southwest Asia, between the Zagros mountains and the Fertile Crescent (Zeder and Hesse, 2000; Naderi et al., 2007; Zeder 2008; Colli et al., 2015). However, a more complex history of goat domestication had been proposed with independent events in the Fertile Crescent and in Asia based on mitochondrial lineages (Luikart et al., 2001; Joshi et al., 2004; Chen et al., 2005).

The overall mean estimated inbreeding coefficient $\left(F_{I S}\right)$ was 0.069 and it varied from 0.029 (SLB) to 0.071 (KOT). The exact test for Hardy-Weinberg equilibrium (HWE) revealed significant deviations $(\mathrm{P}<0.05)$ in 10 out of 75 breed-locus combinations (Table 2 ). 


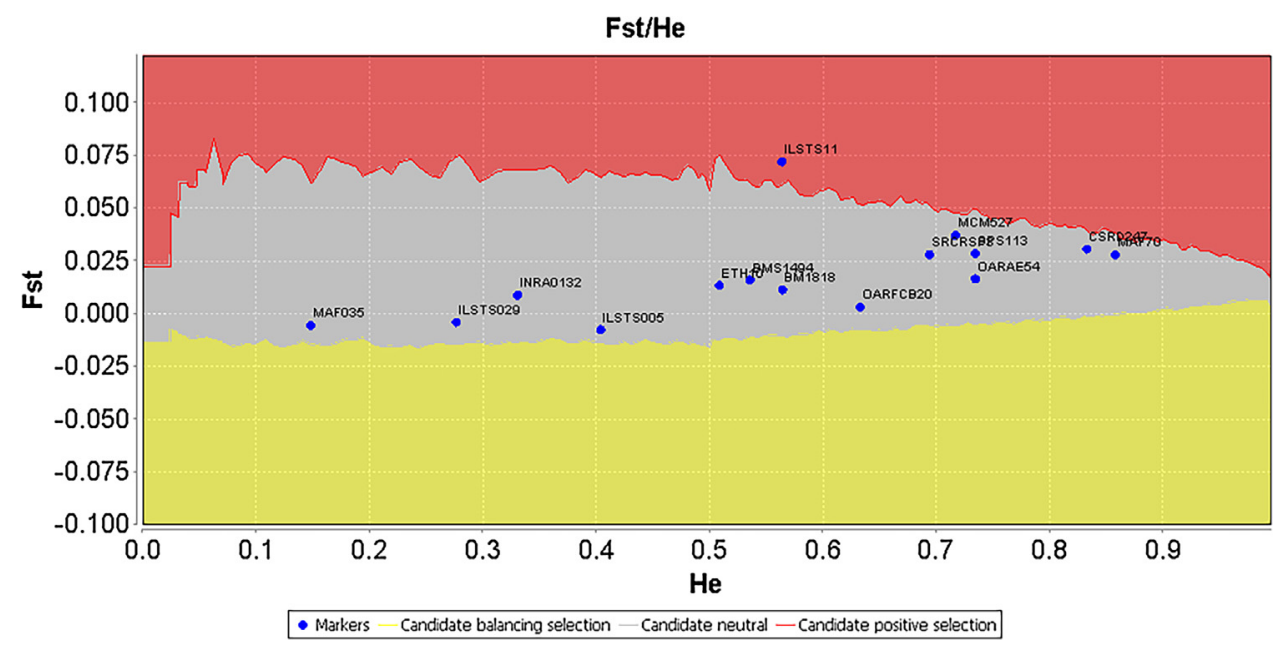

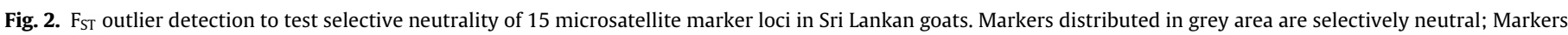

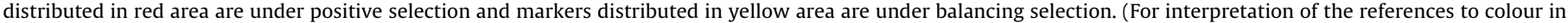
this figure legend, the reader is referred to the web version of this article.)

Table 3

Global F statistics of Sri Lankan goat populations across different microsatellite loci.

\begin{tabular}{llll}
\hline Locus & $\mathrm{F}_{\mathrm{ST}}$ & $\mathrm{F}_{\mathrm{IT}}$ & $\mathrm{F}_{\mathrm{IS}}$ \\
\hline ILSTS029 & -0.004 & 0.035 & 0.039 \\
BMS1494 & 0.017 & 0.069 & 0.053 \\
MAF035 & -0.004 & -0.041 & -0.037 \\
SRCRSP3 & 0.027 & 0.092 & 0.066 \\
BM1818 & 0.009 & 0.016 & 0.007 \\
OARFCB20 & 0.004 & -0.037 & -0.041 \\
OARAE54 & 0.015 & 0.046 & 0.031 \\
ILSTS005 & -0.009 & 0.122 & 0.130 \\
SPS113 & 0.029 & 0.021 & -0.008 \\
CSRD247 & 0.033 & 0.047 & 0.014 \\
INRA0132 & 0.002 & 0.352 & 0.351 \\
MCM527 & 0.035 & 0.089 & 0.057 \\
MAF70 & 0.026 & 0.141 & 0.118 \\
ILSTS11 & 0.060 & 0.058 & -0.002 \\
ETH10 & 0.013 & 0.086 & 0.074 \\
Overall & 0.021 & 0.071 & 0.052 \\
\hline
\end{tabular}

Table 4

Pair-wise F FT (upper triangle) and pair-wise Cavalli-Sforza and Edwards chord distance among Sri Lankan goat populations.

\begin{tabular}{llllll}
\hline & JFL & KOT & SLB & SLS & SNC \\
\hline JFL & - & 0.013 & 0.026 & 0.019 & 0.013 \\
KOT & 0.196 & - & 0.035 & 0.019 & 0.019 \\
SLB & 0.236 & 0.250 & - & 0.022 & 0.029 \\
SLS & 0.214 & 0.202 & 0.234 & - & 0.023 \\
SNC & 0.190 & 0.201 & 0.221 & 0.212 & - \\
\hline
\end{tabular}

Among different loci, INRA132 significantly deviated from HWE in three out of five populations $(\mathrm{P}<0.05)$. With respect to different goat populations, three loci deviated in KOT and JFL goats, two loci in SLB and SLS while one locus in SNC deviated from equilibrium. All these deviations from HWE were due to heterozygosity deficit except for the locus CSRD247 in SLS population. In spite of the absence of pedigree information in individual populations, it was clear as assessed by $\mathrm{F}_{\mathrm{IS}}$, significant heterozygosity deficiency was detected in JFL $\left(\mathrm{F}_{\mathrm{IS}}=0.066 ; P<0.001\right)$ and KOT $\left(\mathrm{F}_{\mathrm{IS}}=0.071 ; P<0.01\right)$ goats, indicating consanguineous mating due to small effective population size and/or influence of selection on the investigated loci. In both the goat populations, selective breeding is seldom practiced; however, to test the influence of natural selection forces operating on the studied loci, $\mathrm{F}_{\mathrm{ST}}$ outlier approach was followed as implemented in LOSITAN. This selection detection strategy evaluates relationship between $\mathrm{F}_{\mathrm{ST}}$ and expected heterozygosity in an island model and identifies outlier loci that have excessively high or low $\mathrm{F}_{\mathrm{ST}}$ compared to neutral expectations (Antao et al., 2008). The results revealed the locus ILSTS11 to be significantly deviating from neutrality (95\% confidence interval; false discovery rate P-value $<0.05$ ) and under positive selection (Fig. 2). This
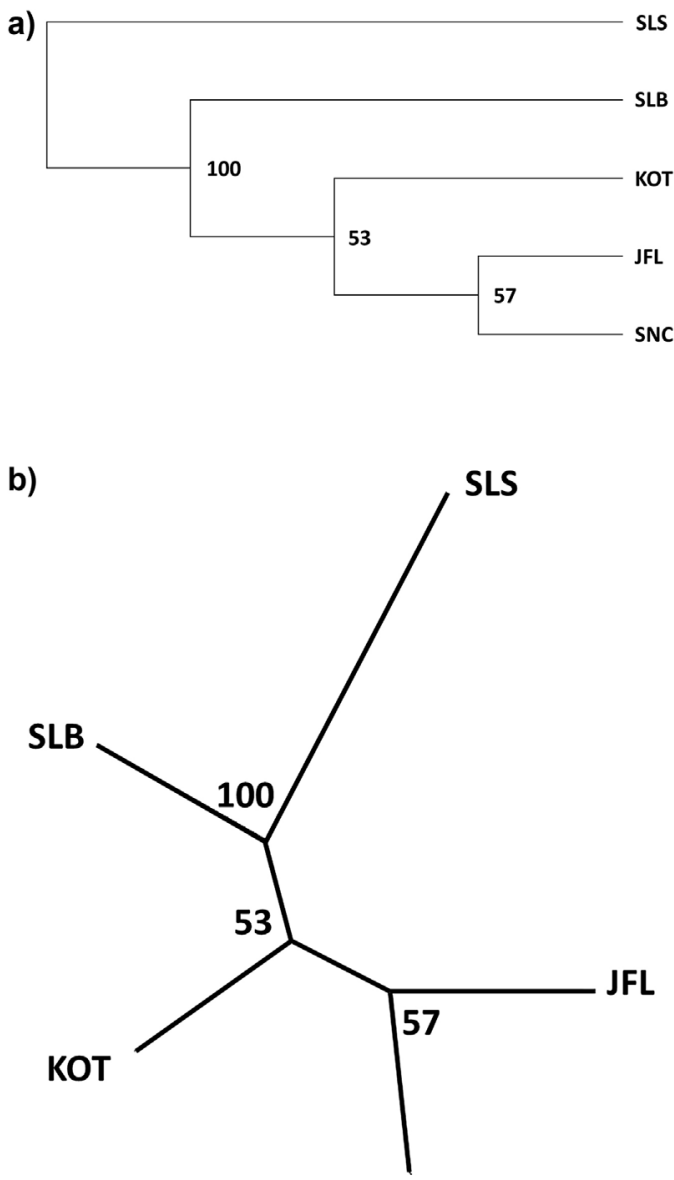

SNC

Fig. 3. UPGMA (a) Dendrogram and (b) Radial tree based on pair-wise Cavalli-Sforza and Edwards chord distance (values at nodes indicate percent bootstrap values). 


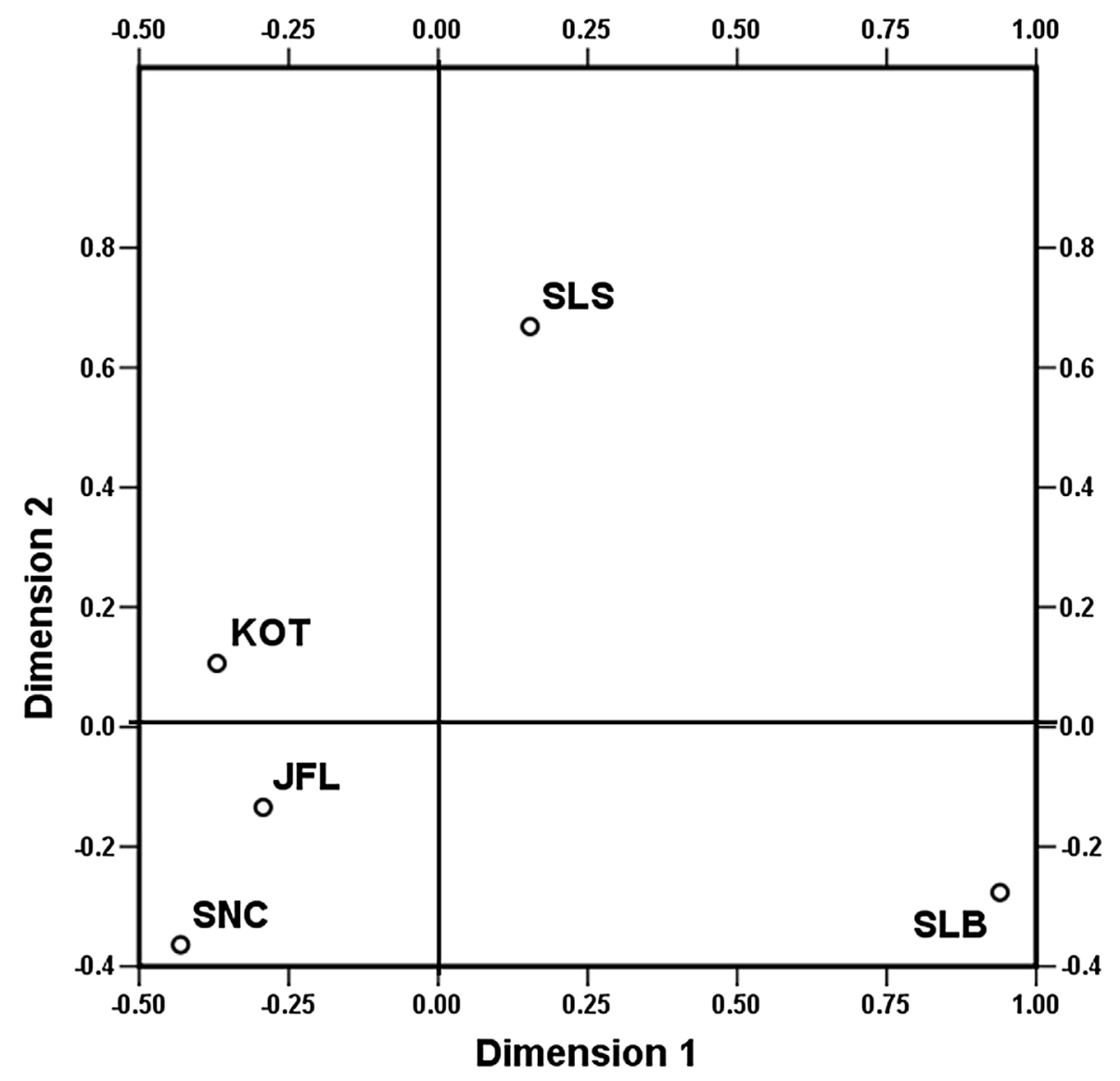

Fig. 4. Multidimensional scaling display of pair-wise $\mathrm{F}_{\mathrm{ST}}$ among different goat breeds (S-Stress $=0.00038$ ).

locus significantly deviated from $\operatorname{HWE}(\mathrm{P}<0.05)$ in JFL goats with an estimated $\mathrm{F}_{\mathrm{IS}}$ of 0.097 . On the other hand, KOT population has evolved from a narrow genetic base and with no vigorous directional selection, and is presently showing a decreasing population trend. Hence, the observed heterozygosity deficiency could be due to small effective population size (Silva et al., 2010) and possible natural selection forces acting on the studied loci (Mekuriaw et al., 2016).

\subsection{Genetic differentiation, phylogeny and population structure}

The global $\mathrm{F}_{\mathrm{ST}}$ was estimated to be 0.021 , indicating that only $2.1 \%$ of the total genetic variation was due to between population differences while $97.9 \%$ of the variation was found within populations (Table 3). The pair-wise $\mathrm{F}_{\mathrm{ST}}$ ranged from 0.013 (JFL-KOT and JFL-SNC) to 0.035 (SLB-KOT). Similarly, pair-wise Cavalli-Sforza and Edwards chord distance varied from 0.190 (JFL-SNC) to 0.250 (SLBKOT) (Table 4). The average estimated effective number of migrants per generation between pairs of populations was considerably high $\left(N_{\mathrm{m}}=3.88\right)$. The pair-wise $\mathrm{N}_{\mathrm{m}}$ estimates among Sri Lankan goat populations are presented in Supplementary Table ST1. The averages for the differentiation indices and genetic distances between pairs of populations were similar to South Indian goat populations (Radhika et al., 2015) while much lower than reported for other groups of goat breeds (Li et al., 2002; Canon et al., 2006; Rout et al., 2008; Agha et al., 2008; Serrano et al., 2009; Murital et al., 2015; Bulut et al., 2016; Elbeltagy et al., 2016). These findings are suggestive of low differentiation and higher rate of migration and gene flow among the populations. This observation is very well supported by the past and the prevailing goat breeding practices in the region. Though the five goat populations were evolved in different geographic locations, in the absence of strict boundaries and narrow expanse of land in the island, the present breeding practices allow for occasional gene flow among populations, although not frequent. Accordingly, the goat populations have limited variability among them. The pair-wise Cavalli-Sforza and Edwards chord distances among goat populations were utilized to draw dendrogram and radial tree (Fig. $3 a$ and $b$ ). The dendrogram showed clustering of JFL and SNC followed by the joining of KOT with a bootstrap value of more than $50 \%$. SLB and SLS were found to be relatively distinct from these goat populations. The phylogenetic clustering of Sri Lankan goat populations was found to follow the pattern of their respective geographical locations. SLS goats are distributed in the southern most region of the island with significant isolation from the rest of goat populations. SLB was evolved as a result of crossbreeding local goats with German Boer to improve growth rate and weight gain for increased meat productivity.

The two dimensional display of MDS plot revealed close genetic proximity of JFL, SNC and KOT goats while SLS and SLB were found to be distinctly placed (Fig. 4). The S-stress value was 0.00038 . The results of MDS analysis broadly supported the phylogeny based clustering of Sri Lankan goat populations. However, it needs to be mentioned, although the MDS display showed the relationships among studied populations, the level of genetic differentiation was relatively low to indicate strong and distinct population structure. The population structure was further investigated using unsupervised model based Bayesian clustering as implemented in STRUCTURE program. The method uses a Bayesian model to capture admixture in populations, with model parameters inferred by Markov Chain Monte Carlo (MCMC) sampling. Fig. 5 illustrates the lack of clustering solutions for each value of $\mathrm{K}$ from 2 to 5 . The proportion of membership for most goats across all the populations was distributed among the assumed number of clusters 


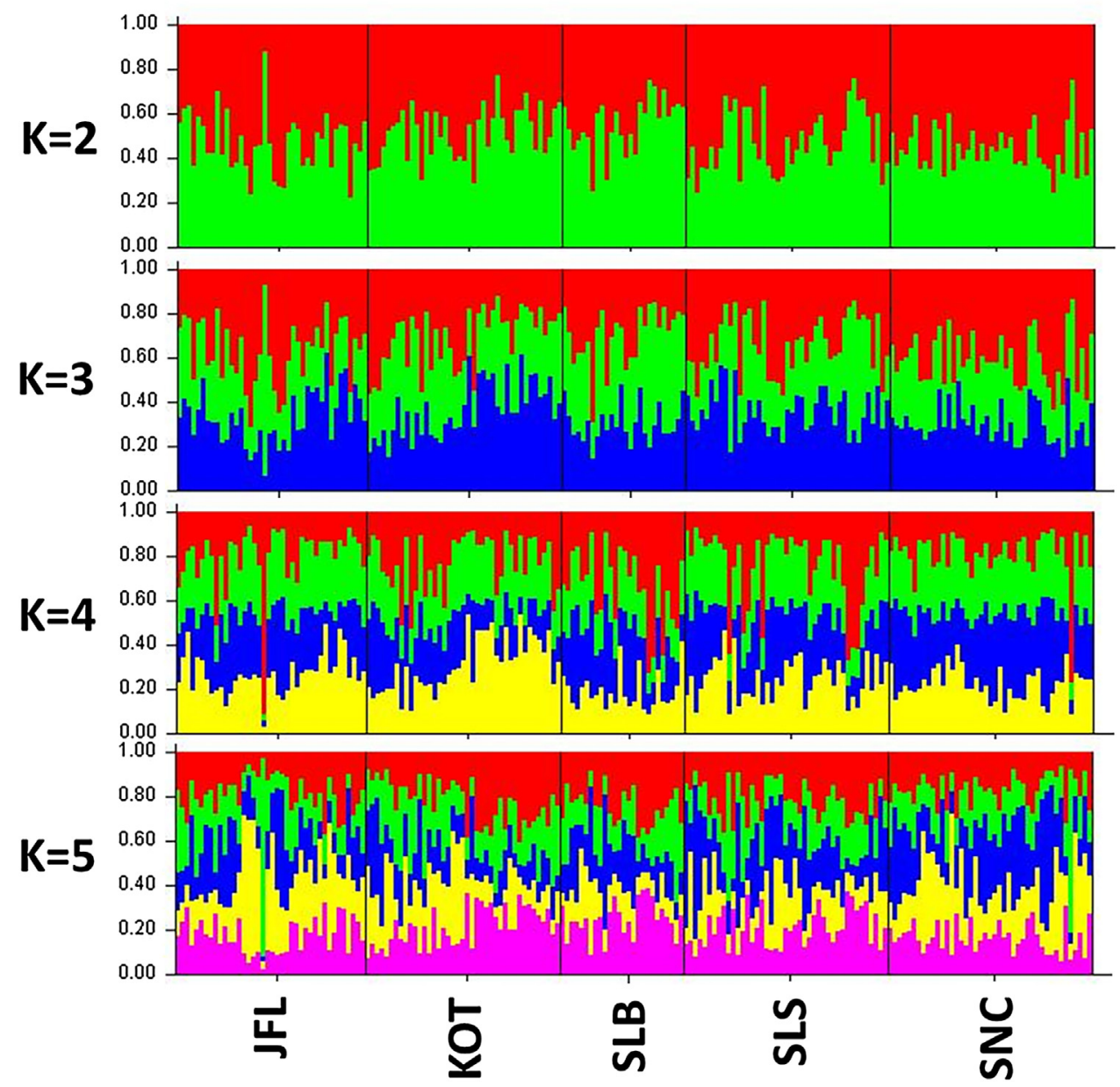

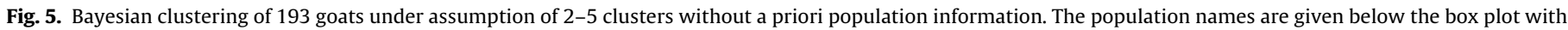
the individuals of different populations separated by vertical black lines.

for each value of K. Such partial membership of individual animals in multiple clusters without being assigned to a single cluster indicates the phenomena of high migration rate and admixture. This also infers that different parts of an individual's genome got inherited from different populations (Shringarpure et al., 2011). The results clearly showed lack of discrete genetic structure in Sri Lankan goats despite significant morphological and phenotypic differences among the studied populations (Supplementary Fig. SF1a-e) (Chandrasiri, 2002; Silva et al., 2010). Interestingly, the Sri Lankan Boer (SLB) goats with considerable exotic inheritance did not cluster distinctly and were found to be continuous with other indigenous goat populations. This could be due to (a) widespread backcrossing of crossbreds (Local X German Boer) with local goats after F1 generation and (b) degree of genetic differentiation assessed by few microsatellite loci in the present study might not be adequate to represent the degree of morphological and phenotypic differentiation among populations (Vahidi et al., 2014).

Neutral markers such as microsatellites could be theoretically blind to the effect of natural selection and human intervened breeding processes that are effective in bringing rapid change in morphology and production traits (Leinonen et al., 2008). Nevertheless, as Vahidi et al., 2014 pointed out, the number of markers included in the study could be not sufficient enough to capture such changes visible in morphology and production. Although the degree of differentiation in quantitative traits $\left(\mathrm{Q}_{\mathrm{ST}}\right.$, the quantitative genetic analogue of $\left.\mathrm{F}_{\mathrm{ST}}\right)$ is highly correlated $(\mathrm{r}=0.87$; Merilaè and Crnokrak, 2001) with degree of genetic differentiation estimated using neu- tral marker variations $\left(\mathrm{F}_{\mathrm{ST}}\right)$, it has been reported that $\mathrm{Q}_{\mathrm{ST}}$ typically exceeds $\mathrm{F}_{\mathrm{ST}}$, suggesting a prominent role for natural selection in accounting for patterns of quantitative trait differentiation among contemporary populations (Leinonen et al., 2013). However, the effects of selection depend on the amount of gene flow occurring between populations. If there is limited gene flow among populations, selection will drive phenotypic divergence, whereas the time since population divergence will drive neutral genetic divergence (Ogden and Thorpe, 2002). When populations are subdivided over a geographical range, local environmental conditions may create spatially and temporally varying selection pressures, thus creating population differentiation (Merilaè and Crnokrak, 2001; Zhan et al., 2005). Alternatively, analysis of native breeds using high density single nucleotide polymorphic (SNP) marker panels may help distinguish neutral and selected genomic regions and narrow the divergence of $\mathrm{Q}_{\mathrm{ST}}$ and $\mathrm{F}_{\mathrm{ST}}$ estimations. Access to large numbers of SNP markers has opened the possibility of estimating quantitative genetic parameters without experimental crosses or access to recorded pedigrees and could help improve the precision of

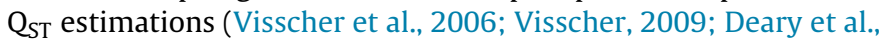
2012). Such additional information may help in decision making on conservation priorities and genetic improvement programs of indigenous populations.

\subsection{Mitochondrial DNA variation}

A 468 bp sequence of mitochondrial DNA D-loop region corresponding to positions $15665-16132$ of the complete 


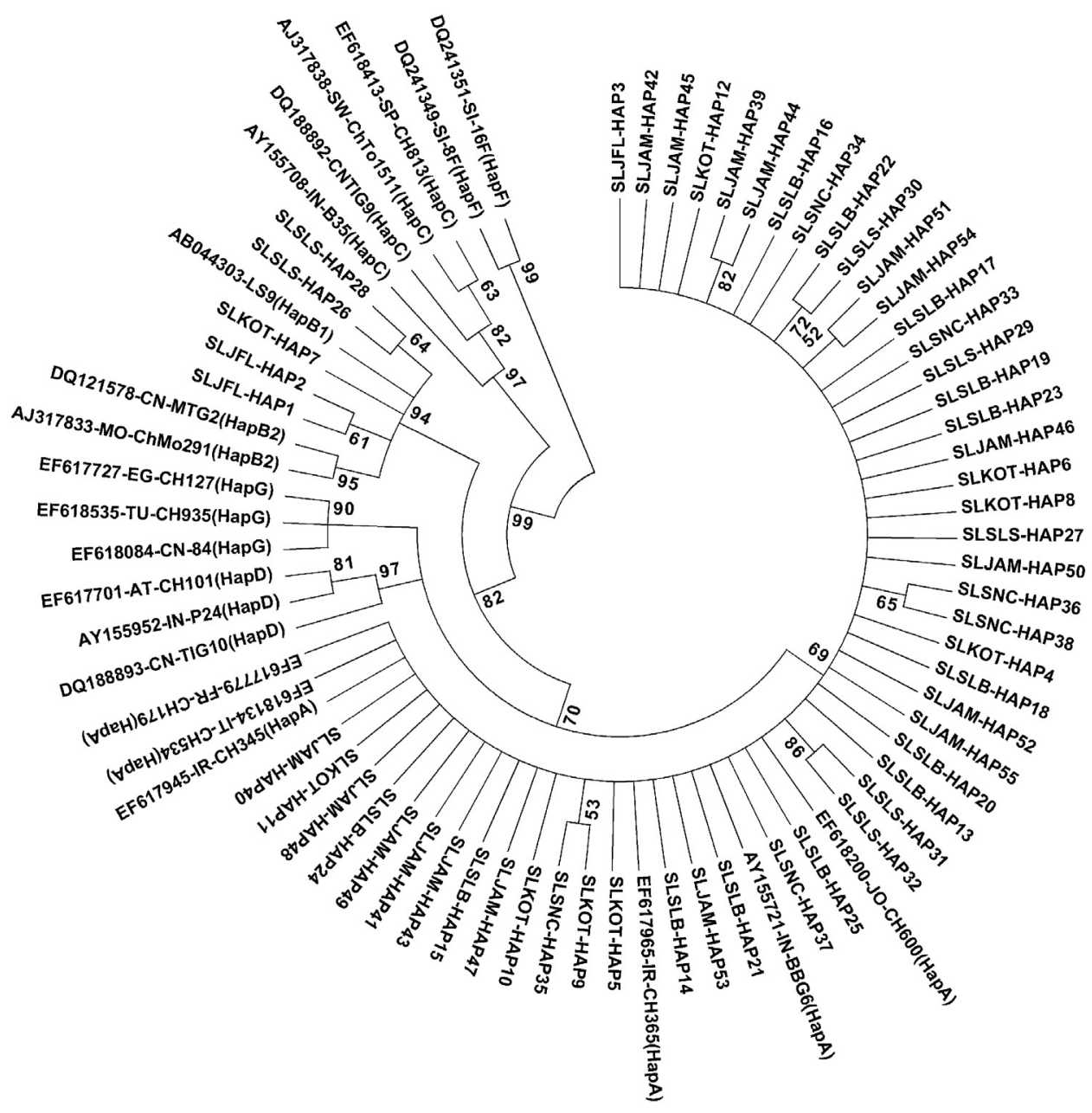

Fig. 6. Maximum likelihood tree of mtDNA D-loop haplotypes of Sri Lankan goats.

mitochondrial genome (NCBI GenBank Accession No. GU229278) was generated in 83 Sri Lankan goats including the crossbred (Jamunapari $\times$ Indigenous) population (SLJAM). All the sequences generated in the study were submitted to NCBI-GenBank and are available under accessions numbers KP671315-KP671397. Overall, the number of polymorphic and parsimony informative sites was 57 and 54, respectively, with a haplotype diversity of 0.977. A total of 55 haplotypes (Supplementary Table ST2) were observed with a nucleotide diversity of 0.0247 and the average number of nucleotide differences was 11.564. Between different goat populations, the haplotype diversity varied from 0.909 (SLJAM) to 1 (SLJFL and SLSNC). Most of the haplotype sharing in Sri Lankan goat populations was observed to be within breeds. Identification of haplogroups revealed the existence of maternal lineages ' $A$ ' and 'B1' in Sri Lankan goats. Haplogroup ' $A$ ' was found to predominate with a frequency of $91.6 \%$ while haplogroup 'B1' was observed in $8.4 \%$ of the goats studied. Both the haplogroups (A and B1) were found in three goat populations SLJFL, SLKOT and SLSLS while haplogroup 'A' alone was observed in SLJAM, SLSLB and SLSNC populations. The high frequency of haplogroup ' $A$ ' in Sri Lankan goats is similar to the observations made in Indian (Joshi et al., 2004), Chinese (Liu et al., 2009; Wang et al., 2015), Eurasian and African goats (Naderi et al., 2007). Haplogroup ' $A$ ' is the most derived and widespread maternal lineage in goats and provides essential piece of information to reconstruct phylogeography, especially in distinguishing ancient and recent displacements of stocks (Doro et al., 2014).
All the reference sequences of haplogroups observed globally (A, B1, B2, C, D, F and G) as suggested by Naderi et al. (2007) was used to construct phylogeny. Phylogenetic analysis of mitochondrial haplotypes revealed two major clusters conforming to their haplogroup classification (Fig. 6). Doro et al. (2014) reported 11 major clades within haplogroup 'A' in Sardinian goats while Colli et al. (2015) reported seven sub-branches within haplogroup 'A'. Although no such major clades were observed within Sri Lankan haplogroup ' $A$ ', six minor clusters were observed with two haplotypes each. To investigate the genetic structure of Sri Lankan goats based on mitochondrial haplotypes, D-loop sequences of 366 Indian goats belonging to nine breeds and one non-descript population available at NCBI were used (Joshi et al., 2004). Considering the geographical and cultural proximity of Sri Lanka with South India, additionally 59 goats belonging to three breeds: Kanni Adu, Kodi Adu and Tellichery, were sequenced and submitted to NCBIGenBank (Accession numbers KP671398-KP671456). Pair-wise F FT was estimated based on haplotype frequency and utilized for principal components analysis (PCA). The first three largest principal components explained $94.7 \%$ of the total variance and the three dimensional scattergram revealed two major clusters. All the major Indian goat breeds including the three South Indian breeds clustered together except for a local non-descript population. Three Sri Lankan goat populations, SLJAM (Jamunapari crossbred), SLSLB (Sri Lankan Boer) and SLSNC (Sri Lanka North Central) that possessed only haplogroup 'A' were found to cluster with Indian breeds 


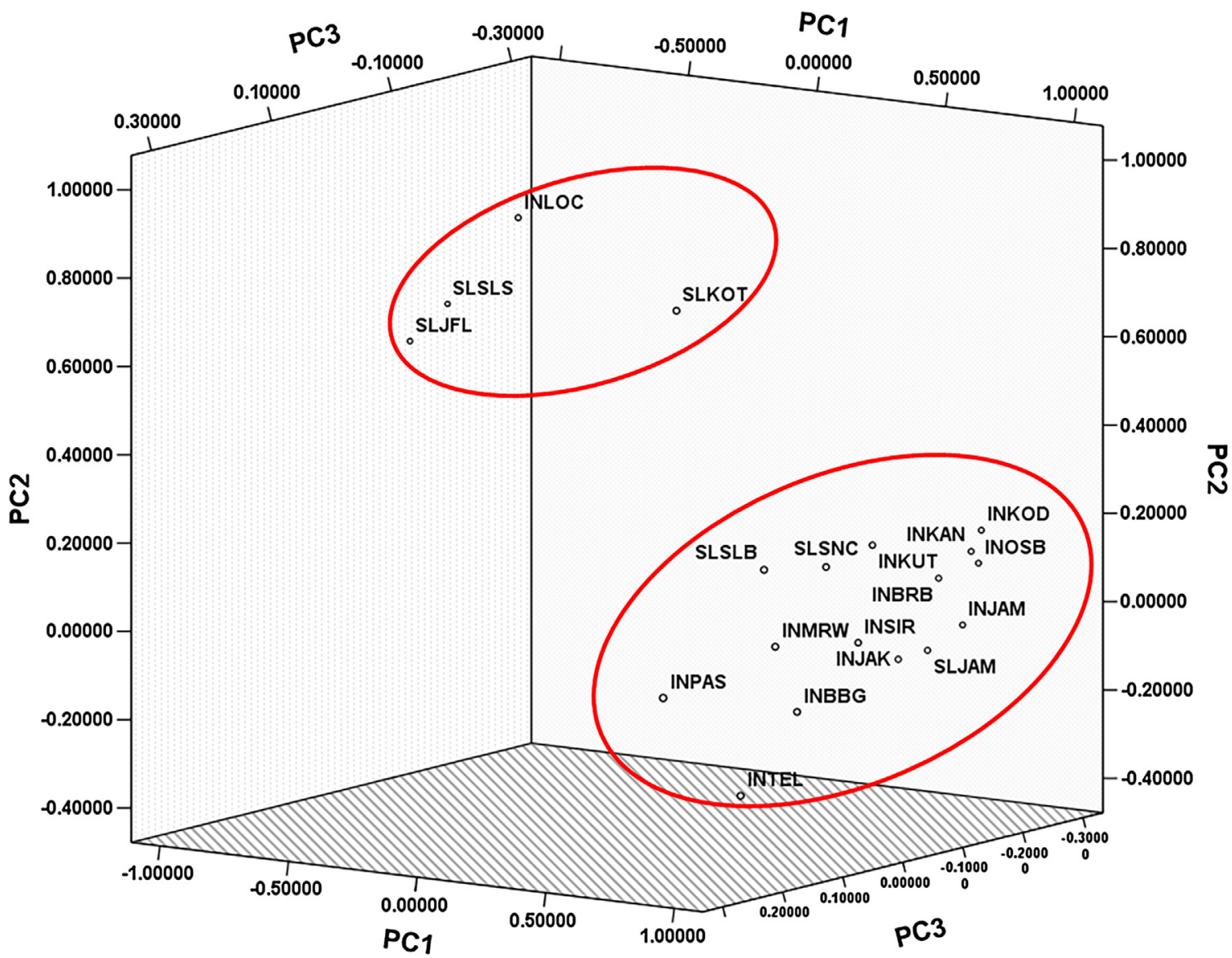

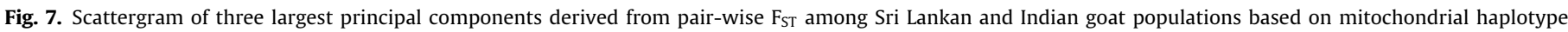
variations (Three largest PCs explain 94.7\% of total variance; 1st PC $=79.83 \%$, 2nd PC $=12.99 \%$, 3rd PC $=1.92 \%$ ).

Table 5

Analysis of molecular variance among mitochondrial DNA haplotypes of Sri Lankan and Indian goat populations.

\begin{tabular}{|c|c|c|c|c|c|c|}
\hline Group & Source of variation & df & Sum of squares & Variance components & Percentage variation & P-value \\
\hline \multirow[t]{2}{*}{ No Grouping } & Among populations & 18 & 324.89 & 0.534 & 11.27 & 0.000 \\
\hline & Within populations & 489 & 2057.03 & 4.207 & 88.73 & 0.000 \\
\hline Grouping I ( 1 - Indian goats; 2 - Sri & Among groups & 1 & 26.32 & 0.053 & 1.11 & 0.019 \\
\hline \multirow[t]{2}{*}{ Lankan goats) } & Among populations within groups & 17 & 298.57 & 0.518 & 10.85 & 0.000 \\
\hline & Within populations & 489 & 2057.03 & 4.207 & 82.75 & 0.000 \\
\hline Grouping II (1 - Indian goats; 2 - & Among groups & 2 & 75.62 & 0.338 & 6.79 & 0.005 \\
\hline SLSLS, SLJFL, SLKOT; 3 - SLSLB, & Among populations within groups & 16 & 249.27 & 0.430 & 8.64 & 0.000 \\
\hline SLSNC, SLJAM) & Within populations & 489 & 2057.03 & 4.207 & 71.26 & 0.000 \\
\hline Grouping III (1 - Indian goats; & Among groups & 1 & 62.25 & 1.278 & 2.65 & 0.000 \\
\hline SLSLB, SLSNC; SLJAM; 2 - SLSLS, & Among populations within groups & 17 & 262.64 & 0419 & 7.09 & 0.000 \\
\hline SLJFL, SLKOT) & Within populations & 489 & 2057.03 & 0.207 & 71.26 & 0.000 \\
\hline
\end{tabular}

(Fig. 7). However, SLJFL (Jaffna Local), SLKOT (Kotukachiya) and SLSLS (Sri Lanka South) goat populations that possessed both haplogroups ' $\mathrm{A}$ ' and 'B' were found to cluster distinctly. However, it needs to be mentioned that Indian goats were found to possess a wide diversity of haplogroups including A, B, C, D and E (Joshi et al., 2004). To further confirm the clustering pattern observed in PCA scattergram, analysis of molecular variance was performed (Table 5). When no grouping was assumed, among population variance was $11.27 \%$. With the assumption of Indian and Sri Lankan goats under two different groups, among group variance was $1.11 \%$ while among population variance within group was $10.85 \%$. When three groups were considered, (1 - Indian goats; 2 - SLSLS, SLJFL and SLKOT; 3 - SLSLB, SLSNC and SLJAM), variance among group increased to $6.79 \%(\mathrm{P}<0.01)$ while the variance among populations within group decreased to $8.64 \%$. When the grouping was assumed following PCA clusters ( 1 - Indian goats, SLSLB, SLSNC, SLJAM; 2 SLJFL, SLKOT, SLSLS), among group variance was 21.65\% ( $\mathrm{P}<0.001)$. The results thus indicated the possible distinct maternal origin of SLJFL, SLKOT and SLSLS populations as compared to SLJAM, SLSLB and SLSNC goats. The genetic structure obtained by AMOVA and PCA scattergram based on mitochondrial DNA haplotypes were broadly similar to the MDS display of pair-wise $\mathrm{F}_{\mathrm{ST}}$ estimated from microsatellite variation, but with few notable exceptions. Given the fact that mitochondrial haplotypes are maternally transmitted and conserved, it could decrease the heterogeneity as a result of the high rates of genetic drift. However, similar patterns of variations shown by the mitochondrial and nuclear markers suggest the absence of strong sex-specific differences in migration among populations. Similar to mitochondrial haplotypes, microsatellite variations depict low levels of genetic heterogeneity, which could 
be resulted not only due to rate of gene flow, which is not vigorous given breeding regime, but also from geographical areas that have not been isolated long enough for differentiation of nuclear markers (Feulner et al., 2004). Thus, MDS clustering was reminiscent of geographical proximity with SLSLS goat population being placed distinctly while SLSNC clustered along with SLJFL and SLKOT. This is understandable as the breed formation is generally believed to be a very late activity with a low time depth vis-à-vis the process of domestication of a livestock species (Bruford et al., 2003; Kumar et al., 2007). Further, the breed differentiation may be the result of genetic drift coupled with intensive selection mainly operating through paternal lineages.

\section{Conclusions}

The results of this study contribute to the knowledge of the genetic diversity and structure of Sri Lankan goat populations, and suggest that they are less diverse than the breeds found in Eurasia and in particular India. Genetic differentiation among populations was low and the phylogenetic clustering pattern was in line with the geographical location of populations. Although pair-wise Cavalli-Sforza and Edwards chord distance clustered Sri Lankan South and Sri Lankan Boer separately from the rest of the populations, Bayesian clustering clearly showed lack of discrete genetic structure in Sri Lankan goat populations despite the presence of significant morphological and phenotypic differences among them. Mitochondrial D-loop sequences revealed significant haplotype diversity with the existence of maternal haplogroups 'A' and 'B1' in Sri Lankan goat populations. Analysis of mitochondrial DNA sequences indicated the possible distinct maternal origin of Jaffna Local, Kotukachchiya and Sri Lankan South as compared to other goat populations. To maintain the present genetic diversity, proper national breeding strategies should be implemented considering within and between population variations. Given the low genetic differentiation among populations, the breed management plan should emphasize sustainable genetic improvement for increased productivity rather than conservation per se. Establishment of breed associations and strengthening existing nucleus breeding farms should be the first step towards management of goat genetic resources in Sri Lanka. If the livestock keepers express their interest in developing and maintaining pure "breeds" according to the definition used for livestock populations in industrialized countries, gene flow among populations and regions should be monitored and avoided to maintain the genetic distinction of the various populations of Sri Lankan goats.

\section{Acknowledgements}

The authors wish to thank the International Atomic Energy Agency (IAEA), Vienna, Austria for funding and technical support under the Coordinated Research Project (CRP) D3.10.25 and the National Science Foundation of Sri Lanka for part funding the research and technical assistance (Grant No. 2007/BT/07). The support provided by the International Livestock Research Institute (ILRI), Nairobi, Kenya and the CAAS-ILRI Joint Laboratory on Livestock and Forage Genetic Resources, Institute of Animal Science, Chinese Academy of Agricultural Sciences (CAAS), Beijing, China is gratefully acknowledged.

\section{Appendix A. Supplementary data}

Supplementary data associated with this article can be found, in the online version, at http://dx.doi.org/10.1016/j.smallrumres. 2016.12.030.

\section{References}

Afroz, M.F., Faruque, M.O., Hussain, S.S., Han, J.L., Paul, B., 2010. Genetic variation and relations in different goat populations of Bangladesh. Bangladesh J. Anim. Sci. 39, 1-8.

Agha, S.H., Pilla, F., Galal, S., Shaat, I., D’Andrea, M., Reale, S., Abdelsalam, A.Z., Li, M.H., 2008. Genetic diversity in Egyptian and Italian goat breeds measured with microsatellite polymorphism. J. Anim. Breed. Genet. 125, 194-200.

Anothaisinthawee, S., Oishi, T., Amano, T., Nomura, K., 2012. Genetic diversity and relationships between indigenous and the original Thai meat goat population based on microsatellite analysis. J. Anim. Genet. 40, 3-8.

Antao, T., Lopes, A., Lopes, R.J., Beja-Pereira, A., Luikart, G., 2008. LOSITAN: A workbench to detect molecular adaptation based on a $\mathrm{F}_{\mathrm{ST}}$-outlier method. BMC Bioinf. 9, 323

Barker, J.S.F., Tan, S.G., Moore, S.S., Mukherjee, T.K., Matheson, J.L., Selvaraj, O.S., 2001. Genetic variation within and relationships among populations of Asian goats (Capra hircus). J. Anim. Breed. Genet. 118, 213-223.

Bruford, M.W., Bradley, D.G., Luikart, G., 2003. DNA markers reveal the complexity of livestock domestication. Nat. Rev. Genet. 4, 900-910.

Bulut, Z., Kurar, E., Ozsensoy, Y., Altunok, V., Nizamlioglu, M., 2016. Genetic diversity of eight domestic goat populations raised in Turkey. BioMed. Res. Int., http://dx.doi.org/10.1155/2016/2830394.

Canon, J., Garcia, D., Garcia-Atance, M.A., Obexer-Ruff, G., Lenstra, J.A., Ajmone-Marsan, P., Dunner, S., The ECONOGENE Consortium, 2006. Geographical partitioning of goat diversity in Europe and the Middle East. Anim. Genet. 37, 327-334.

Chandrasiri, A.D.N., 2002. Country Report on the State of Animal Genetic Resources (Sri Lanka). The Food and Agricultural Organization of the United Nations, Rome.

Chen, S.Y., Su, Y.H., Wu, S.F., Sha, T., Zhang, Y.P., 2005. Mitochondrial diversity and phylogeographic structure of Chinese domestic goats. Mol. Phylogenet. Evol. 37 (3), 804-814.

Colli, L., Lancioni, H., Cardinali, I., Olivieri, A., Capodiferro, M.R., Pellecchia, M., Rzepus, M., Zamani, W., Naderi, S., Gandini, F., Vahidi, S.M.F., Agha, S., Randi, E. Battaglia, B., Sardina, M.T., Portolano, B., Rezaei, H.R., Lymberakis, P., Boyer, F., Coissac, E., Pompanon, F., Taberlet, P., Marsan, P.A., Achilli, A., 2015. Whole mitochondrial genomes unveil the impact of domestication on goat matrilineal variability. BMC Genom. 16, 1115

Deary, I.J., Yang, J., Davies, G., Harris, S.E., Tenesa, A., Liewald, D., Luciano, M., Lopez, L.M., Gow, A.J., Corley, J., Redmond, P., Fox, H.C., Rowe, S.J., Haggarty, P., McNeill, G., Goddard, M.E., Porteous, D.J., Whalley, L.J., Starr, J.M., Visscher, P.M., 2012. Genetic contributions to stability and change in intelligence from childhood to old age. Nature 482, 212-215.

Department of Animal Production and Health, 2010. The National Animal Breeding Policy; the Guidelines and Strategies for Livestock in Sri Lanka, Ministry of Livestock \& Rural Community Development and Department of Animal Production and Health, P O Box 13, Gatambe, Sri Lanka.

Department of Animal Production and Health, 2010. Annual Report-2010. Department of Animal Production and Health, P O Box 13, Gatambe, Sri Lanka. http://www.daph.gov.lk/web/images/pdf/2010.pdf; Accessed 15 January 2014

Department of Census and Statistics, 2011. National Livestock Statistics, Agriculture and Environment Statistics Division, Department of Census and Statistics, Colombo, Sri Lanka. http://www.statistics.gov.lk/agriculture/ Livestock/Livestock Statistics.html; Accessed 15 January 2014.

Dieringer, D., Schlotterer, C., 2003. MICROSATELLITE ANALYZER (MSA): a platform independent analysis tool for large microsatellite data sets. Mol. Ecol. Notes 3, $167-169$.

Doro, M.G., Piras, D., Leoni, G.G., Casu, G., Vaccargiu, S., Parracciani, D., Naitana, S., Pirastu, M., Novelletto, A., 2014. Phylogeny and patterns of diversity of goat mtDNA haplogroup A revealed by resequencing complete mitogenomes. PLoS One 9 (4), e95969, http://dx.doi.org/10.1371/journal.pone.0095969.

Elbeltagy, A.R., Aboul-Naga, A.M., Hassen, H., Solouma, G.M., Rischkowsky, B., Mwacharo, J.M., 2016. Genetic diversity and structure of goats within an early livestock dispersal area in Eastern North Africa. Afr. J. Biotechnol. 15, 431-441.

Excoffier, L., Laval, G., Schneider, S., 2005. Arlequin ver.3: 0: An integrated software package for population genetics data analysis. Evol. Bioinform. Online 1, 47-50.

FAO, 2011. Molecular genetic characterization of animal genetic resources. FAO Animal Production and Health Guidelines. No. 9. Rome.

Felsenstein, J., 1993. PHYLIP: Phylogeny Inference Package, Version 3.5. Department of Genetics, Washington University, Seattle, Washington.

Feulner, P.G.D., Bielfeldt, W., Zachos, F.E., Bradvarovic, J., Eckert, I., Hartl, G.B., 2004 Mitochondrial DNA and microsatellite analyses of the genetic status of the presumed subspecies Cervus elaphus montanus (Carpathian red deer). Heredity 2004 (93), 299-306, http://dx.doi.org/10.1038/sj.hdy.6800504.

Jayasinghe, M.C., Dematawewa, C.M.B., Silva, L.P., Premasundara, A.S., 2003. Prediction of live weight from morphometric measurements in goats. Proceedings of the 59th Annual Sessions of the Sri Lanka Association for the Advancement of Sciences, P 74.

Joshi, M.B., Rout, P.K., Mandal, A.K., Tyler-Smith, C., Singh, L., Thangaraj, K., 2004. Phylogeography and origin of Indian domestic goats. Mol. Biol. Evol. 21 (3), 454-462.

Kim, K.S., Yeo, J.S., Lee, J.W., Kim, J.W., Choi, C.B., 2002. Genetic diversity of goats from Korea and China using microsatellite analysis. Asian Aust. J. Anim. Sci. 15, 461-465.

Kumar, S., Nagarajan, M., Sandhu, S., Kumar, N., Behl, V., 2007. Phylogeography and domestication of Indian river buffalo. BMC Evol. Biol. 7, 186-193. 
Leinonen, T., O'Hara, R.B., Cano, J.M., Merilä, J., 2008. Comparative studies of quantitative trait and neutral marker divergence: a meta-analysis. J. Evol. Biol $21,1-17$.

Leinonen, T., McCairns, R.J.S., O’Hara, R.B., Merilä, J., 2013. QST-FST comparisons: evolutionary and ecological insights from genomic heterogeneity. Nat. Rev. Genet. 14, 179-190.

Lenstra, J.A., Tigchelaar, J., Biebach, I., Econogene Consortium, Hallsson, J.H. Kantanen, J., Nielsen, V.H., Pompanon, F., Naderi, S., Rezaei, H.-R., Sæther, N., Ertugrul, O., Grossen, C., Camenisch, G., Vos-Loohuis, M., van Straten, M., de Poel, E.A., Windig, J., Oldenbroek, K., 2016. Microsatellite diversity of the Nordic type of goats in relation to breed conservation: how relevant is pure ancestry? J. Anim. Breed. Genet., http://dx.doi.org/10.1111/jbg.12226 (in press).

Li, M.H., Zhao, S.H., Bian, C., Wang, H.S., Wei, H., Liu, B., Yu, M., Fan, B., Chen, S.L., Zhu, M.J., Li, S.J., Xiong, T.A., Li, K., 2002. Genetic relationships among twelve Chinese indigenous goat populations based on microsatellite analysis. Genet. Sel. Evol. 34, 729-744.

Liu, Y.P., Cao, S.X., Chen, S.Y., Yao, Y.G., Liu, T.Z., 2009. Genetic diversity of Chinese domestic goat based on the mitochondrial DNA sequence variation. J. Anim. Breed. Genet. 126, 80-89.

Luikart, G., Gielly, L., Excoffier, L., Vigne, J.D., Bouvet, J., Taberlet, P., 2001. Multiple maternal origins and weak phylogeographic structure in domestic goats. Proc. Natl. Acad. Sci. U. S. A. 98, 5927-5932.

Marini, A.A.B., Hifzan, R.M., Tan, S.G., Panandam, J.M., 2014. Assessment of genetic diversity on goat breeds in Malaysia using microsatellite markers. Malays. J. Anim. Sci. 17, 19-26.

Mekuriaw, G., Gizaw, S., Dessie, T., Mwai, O., Djikeng, A., Tesfaye, K., 2016. A review on current knowledge of genetic diversity of domestic goats (Capra hircus) identified by microsatellite loci: how those efforts are strong to support the breeding programs? J. Life Sci. Biomed. 6, 22-32.

Merilaè, J., Crnokrak, P., 2001. Comparison of genetic differentiation at marker loci and quantitative traits. J. Evol. Biol. 14, 892-903.

Miller, S.A., Dykes, D.D., Polesky, H.F., 1988. A simple salting out procedure for extracting DNA from human nucleated cells. Nucl. Acids Res. 16, 1215.

Murital, I., Afolayan, O., Bemji, M.N., Dadi, O., Landi, V., Martinez, A., Delgado, J.V., Adebambo, O.A., Aina, A.B.J., Adebambo, A.O., 2015. Genetic diversity and population structure of Nigerian indigenous goat using DNA microsatellite markers. Arch. Zootec. 64, 93-98

Naderi, S., Rezaei, H.-R., Taberlet, P., Zundel, S., Rafat, S.-A., Naghash, H.-R., El-Barody, M.A.A., Ertugrul, O., Pompanon, F., ECONOGENE Consortium, 2007. Large-scale mitochondrial DNA analysis of the domestic goat reveals six haplogroups with high diversity. PLoS One 2 (10), e1012, http://dx.doi.org/10. 1371/journal.pone.0001012.

Ogden, R., Thorpe, R.S., 2002. Molecular evidence for ecological speciation in tropical habitats. Proc. Natl. Acad. Sci. U. S. A. 99, 13612-13615.

Pritchard, J.K., Stephens, M., Donnelly, P., 2000. Inference of population structure using multilocus genotype data. Genetics 155, 945-959.

Radhika, G., Raghavan, K.C., Aravindakshan, T.V., Thirupathy, V., 2015. Genetic diversity and population structure analysis of native and crossbred goat genetic groups of Kerala, India. Small Rumin. Res. 131, 50-57.
Rout, P.K., Joshi, M.B., Mandal, A., Laloe, D., Singh, L., Thangaraj, K., 2008. Microsatellite based phylogeny of Indian domestic goats. BMC Genet. 9, 11. Rozas, J., 2009. DNA sequence polymorphism analysis using DSP. Methods Mol. Biol. 537, 337-350.

Serrano, M., Calvo, J.H., Martínez, M., Marcos-Carcavilla, A., Cuevas, J., González, C., Jurado, J.J., de Tejada, P.D., 2009. Microsatellite based genetic diversity and population structure of the endangered Spanish Guadarrama goat breed. BMC Genet. 29 (10), 61

Shringarpure, S., Won, D., Xing, E.P., 2011. StructHDP: automatic inference of number of clusters and population structure from admixed genotype data. Bioinformatics 27, i324-i332.

Silva, P., Dematawewa, C.M.B., Goonawardena, A., Chandrasiri, N., Pushpakumara, A., 2009. Production systems and characteristics of indigenous small ruminants in Sri Lanka. In: Paper Presented at the International Symposium on Sustainable Improvement of Animal Production and Health, FAO/IAEA joint program to be held 9-11 June, 2009, Austria, Vienna.

Silva, P., Dematawewa, C.M.B., Chandrasiri, N., 2010. Farm animal genetic resources (Chapter 1). In: Indigenous Animal Genetic Resources of Sri Lanka-Status, potential and opportunities, Silva P., (Ed.), GEF-UNEP-ILRI-FAnGR Asia Project (ISBN 978-955-589-120-2).

Tamura, K., Peterson, D., Peterson, N., Stecher, G., Nei, M., Kumar, S., 2011. MEGA5: molecular evolutionary genetics analysis using maximum likelihood, evolutionary distance, and maximum parsimony methods. Mol. Biol. Evol. 28, 2731-2739.

Vahidi, S.M., Tarang, A.R., Naqvi, A.N., Anbaran, M.F., Boettcher, P., Joost, S., Colli, L. Garcia, J.F., Ajmone-Marsan, P., 2014. Investigation of the genetic diversity of domestic Capra hricus breeds reared within an early goat domestication area in Iran. Genet. Sel. Evol. 46, 27.

Visscher, P.M., Medland, S.E., Ferreira, M.A.R., Morley, K.I., Zhu, G., Cornes, B.K., Montgomery, G.W., Martin, N.G., 2006. Assumption-free estimation of heritability from genome-wide identity-by-descent sharing between full siblings. PLoS Genet. 2 (3), e41, http://dx.doi.org/10.1371/journal.pgen. 0020041.

Visscher, P.M., 2009. Whole genome approaches to quantitative genetics. Genetica 136, 351-358.

Wang, G.Z., Pi, X.S., Ji, Z.B., Qin, Z.J., Hou, L., Chao, T.L., Wang, J.M., 2015. Investigation of the diversity and origins of Chinese dairy goats via the mitochondrial DNA D-loop. J. Anim. Sci. 93, 949-955.

Zeder, M., Hesse, B., 2000. The initial domestication of goats (Capra hircus) in the zagros Mountains 10,000 years ago. Sciences 287, 2254-2257.

Zeder, M.A., 2008. Domestication and early agriculture in the Mediterranean Basin: origins, diffusion and impact. Proc. Natl. Acad. Sci. U. S. A. 105, 11597-11604.

Zhan, J., Linde, C.C., Jü rgens, T., Merz, U., Steinebrunner, F., McDonald, B.A., 2005. Variation for neutral markers is correlated with variation for quantitative traits in the plant pathogenic fungus Mycosphaerella graminicola. Mol. Ecol. 14, 2683-2693. 